\title{
Efficient oil/saltwater separation using a highly permeable and fouling-resistant all-inorganic nanocomposite membrane
}

\author{
Rand Elshorafa ${ }^{1} \cdot$ Jayaprakash Saththasivam $^{2} \cdot$ Zhaoyang Liu $^{2}$ (D) $\cdot$ Said Ahzi ${ }^{2}$
}

Received: 29 August 2019 / Accepted: 6 February 2020 / Published online: 19 February 2020

(C) The Author(s) 2020

\begin{abstract}
Although it is still a great challenge, developing oil-/water-separating membranes that combine the advantages of high separation efficiency, salty environments tolerance, and fouling resistance are highly demanded for marine oil spill cleanups and oil-/gasproduced water treatment. Here, we report a new type of all-inorganic nanostructured membrane, which is composed of titanate nanofibers and $\mathrm{SiO}_{2}$ particulate gel for efficient and stable oil/saltwater separation. The nanoporous and interconnected network structure constructed with titanate nanofibers is the key to ensure the high separation efficiency and high water flux of the new membrane. The $\mathrm{SiO}_{2}$ gel is used as a binder to offer mechanical flexibility and integrity for this type of all-inorganic membrane. The new membrane displays a high oil/water separation efficiency of above $99.5 \%$ with oil content in treated effluent lower than US environmental discharge standards (42 ppm) and high water permeation flux of $1600 \mathrm{LMH} / \mathrm{bar}$ under low operation pressure. The new membrane also demonstrates outstanding durability in the environment of different salinities, and it has a good resistance for oil fouling due to its excellent underwater superoleophobicity with an oil contact angle above $150^{\circ}$. Most importantly, the underwater superoleophobic properties can be well maintained after being repeatedly reused. The excellent environmental durability, oil-fouling resistance, high separation efficiency, and facile fabrication process for this new type of membrane render great potential for industrial application in treating produced water.
\end{abstract}

Keywords Membrane separation $\cdot$ Oily wastewater $\cdot$ Superoleophobic $\cdot$ Nanomaterials $\cdot$ Fouling resistance

\section{Introduction}

Oil pollution is a serious issue faced globally because of the large amounts of oily and salty wastewater caused by frequent marine oil spill accidents and oil exploitation/production/

Editorial Responsibility: Angeles Blanco

Electronic supplementary material The online version of this article (https://doi.org/10.1007/s11356-020-08021-x) contains supplementary material, which is available to authorized users.

\section{Zhaoyang Liu zhliu@hbku.edu.qa \\ $\triangle$ Said Ahzi sahzi@hbku.edu.qa}

1 Division of Sustainable Development, College of Science and Engineering, Hamad Bin Khalifa University, Education City, P.O. Box 5825, Doha, Qatar

2 Qatar Environment and Energy Research Institute, Hamad Bin Khalifa University, Qatar Foundation, P.O. Box 5825, Doha, Qatar refinery activities (Qin et al. 2015; Wang et al. 2017a). Regulations enacted by the US Environmental Protection Agency (EPA) limit the discharge of oil in the effluents to a maximum of $42 \mathrm{mg} / \mathrm{L}$ (Anon 2010). Therefore, it is in great demand to develop effective and sustainable techniques to treat oil-polluted wastewater in order to satisfy the stringent regulation and preserve the environment. Conventional techniques for oil/water separation, such as the hydrocyclone and air floatation, suffer some drawbacks including either low separation efficiency or high operation cost (Qin et al. 2017; Wang et al. 2017b). Membrane techniques, such as microfiltration (MF), ultrafiltration (UF), and nanofiltration (NF), which operate with "size-sieving" effect, have been widely used for water purification (Zhang et al. 2013, 2014). UF membranes are very effective in separating stabilized oil emulsions and especially for removing oil droplets with sizes in the micrometer range to produce water with low oil concentrations. However, commercial UF membranes suffer from severe fouling or low fluxes which result from pore plugging by oil droplets and segregated pore structures, and this significantly limits their service time and degrades their separation 
performance in practical applications (Obaid et al. 2018; Shi et al. 2013).

Recently, superwetting membranes have been demonstrated for efficient oil/water separation by designing superhydrophobic-superoleophilic or superhydrophilicsuperoleophobic surfaces in conjunction with surface chemistry and roughness (Zhu et al. 2014). For example, a Teflon (PTFE)-coated mesh film with superhydrophobicity was reported for the separation of oil and water mixtures (Feng et al. 2004). However, these hydrophobic membranes are easy to be fouled by oil, resulting in a quick decline of both water flux and separation efficiency. Therefore, superhydrophilic and superoleophobic membranes are more suitable for the separation of water-rich oil/water mixtures or emulsions. Under the inspiration of fish scales, high-energy materials with water-favoring property were proposed for the construction of underwater superoleophobic membrane surfaces. For example, hydrogelcoated mesh was fabricated with underwater superoleophobicity for separating oil/water mixtures and surfactant-stabilized emulsions (Xue et al. 2011; Zhang et al. 2018). However, these polymer-based approaches have weaknesses in their consideration of practical applications, including the stability of polymeric coating under severe conditions as well as long-term preservation for reuse (Sun et al. 2012). Until now, superoleophobic membranes for oil/water separation with high separation efficiency, superior oil-fouling resistance, and high environmental durability are still barely applied in industry.

In this study, we report a new all-inorganic nanocomposite membrane for oil/saltwater separation. The new membrane is composed of titanate nanofiber and silica nanoparticulate gel. The nanofiber-constructed network membrane presents high separation efficiency for oil/saltwater emulsions with oil residual in the filtrates lower than environmental discharge standards (42 ppm). The silica gel coating ensures the flexibility and integrity of this all-inorganic membrane. Meanwhile, the membrane shows excellent antifouling properties due to its underwater superoleophobicity. Most importantly, this allinorganic membrane exhibits good durability under harsh environments without a decline in terms of both water flux and separation efficiency. Its excellent oil/water separation efficiency, durability, fouling resistance, and low-cost fabrication render this new all-inorganic nanocomposite membrane a great potential for practical industrial applications.

\section{Material and methods}

\section{Materials}

All the chemicals used in this study (titanium dioxide (P25) $\left(\mathrm{TiO}_{2}\right)$, ethanol tetraethyl orthosilicate (TEOS) $\mathrm{Si}\left(\mathrm{OC}_{2} \mathrm{H}_{5}\right)_{4}$, ethanol $\left(\mathrm{CH}_{3} \mathrm{CH}_{2} \mathrm{OH}\right)$, ammonium hydroxide $\left(\mathrm{NH}_{4} \mathrm{OH}\right)$, n-hexane $\mathrm{C}_{6} \mathrm{H}_{14}$, and n-Octane $\mathrm{C}_{8} \mathrm{H}_{18}$ were purchased from Sigma Aldrich. In addition to that, DI water was used.

\section{Instruments and characterization}

The concentration of oil in the feed and filtrate samples was analyzed by measuring the total organic carbon using TOC analyzer (Shimadzu, TOC-L, Japan). The oil droplet size and distribution in the feed was measured by using a Visual Process Analyzer (JORIN-ViPA). The surface morphology of the membrane was analyzed by using scanning electron microscopy (SEM, FEI Corp.), while X-ray diffraction instrument (XRD, Bruker D8 Advance, Bruker-AXS, Germany) was used to determine the crystal structure of the membrane materials. The hydrophilicity/hydrophobicity properties of the membrane were obtained by measuring the water contact angles by using an advanced goniometer (Rame-hart A100, USA).

\section{Materials preparation}

\section{Titanium nanofibers preparation}

Titanium (Ti) nanofibers were prepared as per the procedure described by Jung et.al (2014). Firstly, $7.5 \mathrm{mg} / \mathrm{mL}$ of $\mathrm{TiO}_{2}$ nanoparticle (anatase P25) solution was prepared by adding $0.375 \mathrm{~g}$ of $\mathrm{TiO}_{2}$ nanoparticles to $50 \mathrm{ml}$ of a $10 \mathrm{M} \mathrm{NaOH}$ solution. The solution was well mixed for $30 \mathrm{~min}$ and then transferred into an autoclave where it was placed in a mechanical convection oven for 4 days at $220^{\circ} \mathrm{C}$. The hydrothermal reaction between $\mathrm{TiO}_{2}$ particles and $\mathrm{NaOH}$ resulted in the formation of titanate nanofiber hydrogels. The titanate nanofibers (TiNFs) were cooled at room temperature and washed multiple times using deionized water to neutralize the $\mathrm{pH}$. The solution was then filtered, dried overnight, and stored at room temperature.

\section{$\mathrm{SiO}_{2}$ nanoparticles preparation}

In this work, hydrophilic $\mathrm{SiO}_{2}$ nanoparticles were synthesized by adopting the method used by Cai et.al (2014) where TEOS, ethanol, and ammonia were used as a precursor, a solvent, and a catalyst, respectively. Firstly, $1 \mathrm{~mol}$ of TEOS was mixed with $1 \mathrm{~mol}$ of ethanol for $30 \mathrm{~min}$ using a magnetic stirrer at room temperature. Then, $115.8 \mathrm{~mol}$ of water and $0.01 \mathrm{~mol}$ $\mathrm{NH}_{3}$ were added and mixed for $8 \mathrm{~h}$ using a magnetic stirrer at $40{ }^{\circ} \mathrm{C}$. The resulting SNP solution was then cooled down to room temperature prior to the membrane deposition.

\section{Free-standing $\mathrm{TiNF} / \mathrm{SiO}_{2}$ membrane preparation}

$\mathrm{TiNF} / \mathrm{SiO}_{2}$ membrane was fabricated using a vacuum filtration apparatus, where a premixed solution that contained 

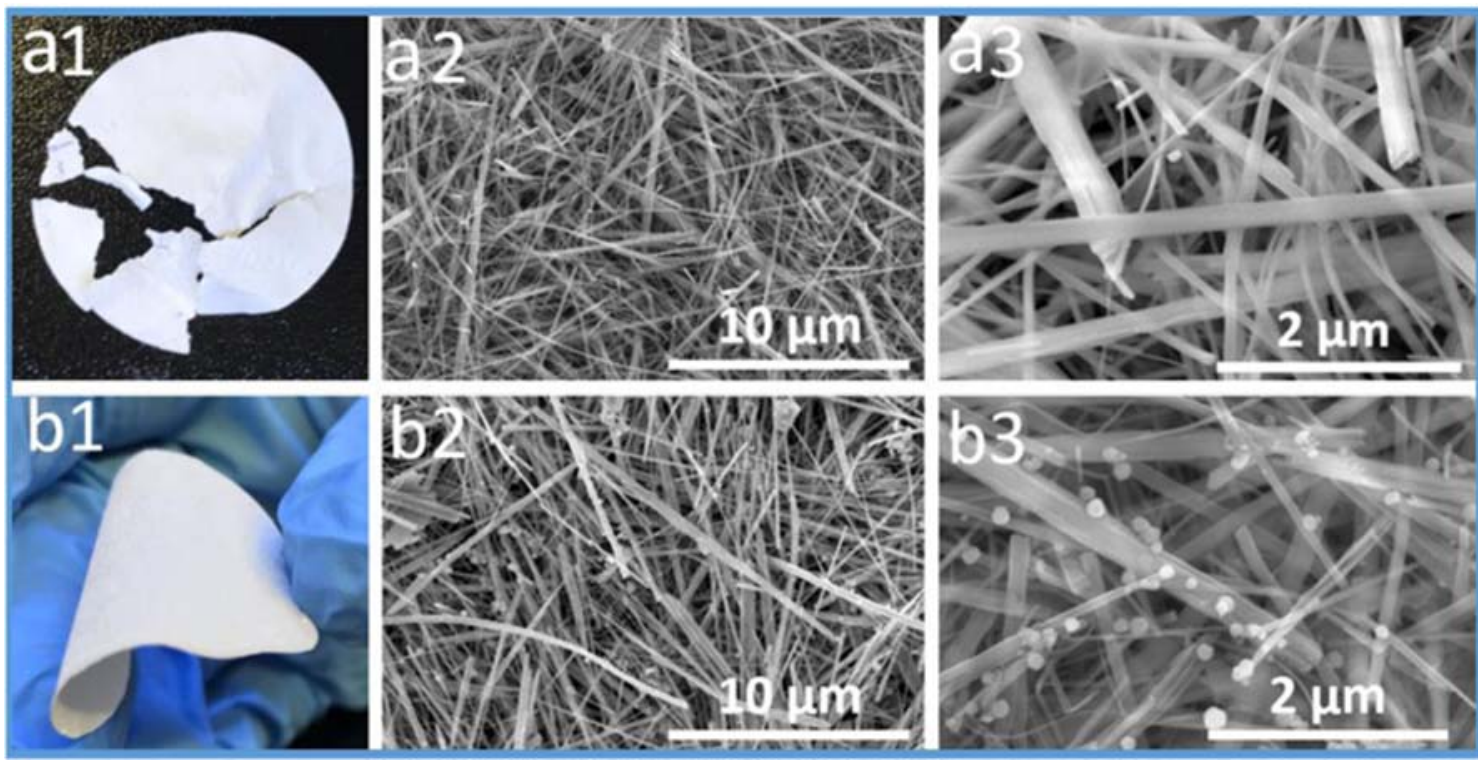

Fig. 1 a1 A photo of the TNF membrane made out of pure titanate nanofibers showing the fragility of the TNF membrane. a2 An SEM image of the TNF membrane surface material showing the interconnected nanoporous structure. a3 An SEM image with higher magnification of the TNF membrane surface. b1 A photo of a freestanding TNFS membrane made of titanate nanofibers and silica nanoparticulate gel showing the flexibility of the TNFS membrane. b2 An SEM image of the TNFS membrane surface showing the interconnected nanoporous structure. b3 An SEM image with higher magnification of the TNFS membrane surface showing the titanate nanofibers bonding with the silica nanoparticulate gel

\section{Preparation of oil-in-water emulsion}

A stable oil-in-water emulsion can be prepared using a sonication technique (Sakai 2008). Firstly, $1 \mathrm{~mL}$ of oil was mixed with $45 \mathrm{~mL}$ of deionized water and then sonicated by using an ultrasonic water bath for $5 \mathrm{~min}$. The resulted emulsion was then further diluted with deionized water to a total volume of $100 \mathrm{ml}$ (Kayvani et al. 2018) to achieve a final concentration of $1 \% \mathrm{v} / \mathrm{v}$ oil-in-water emulsion. In this study, oil-in-water emulsions were prepared using different types of oils, namely, sunflower oil, diesel,
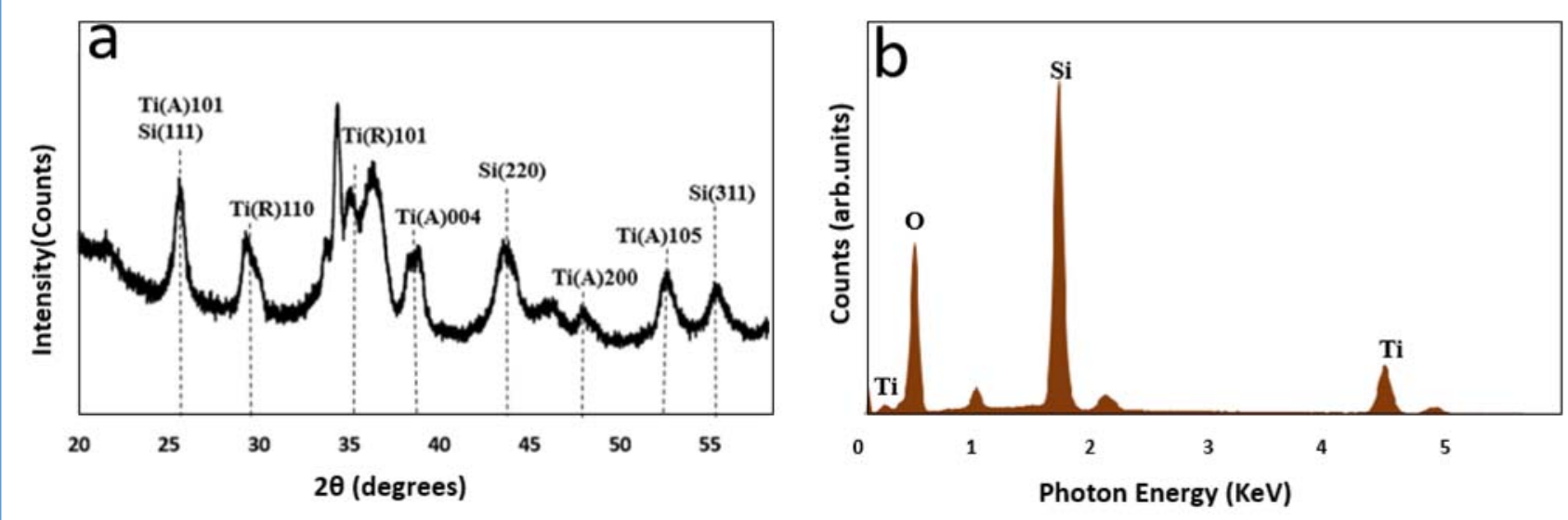

Fig. 2 a An XRD spectra of the TNFS membrane. The major peaks indicate the presence of titanate and silica in the membrane. $\mathbf{b}$ An EDS analysis of the TNFS membrane 


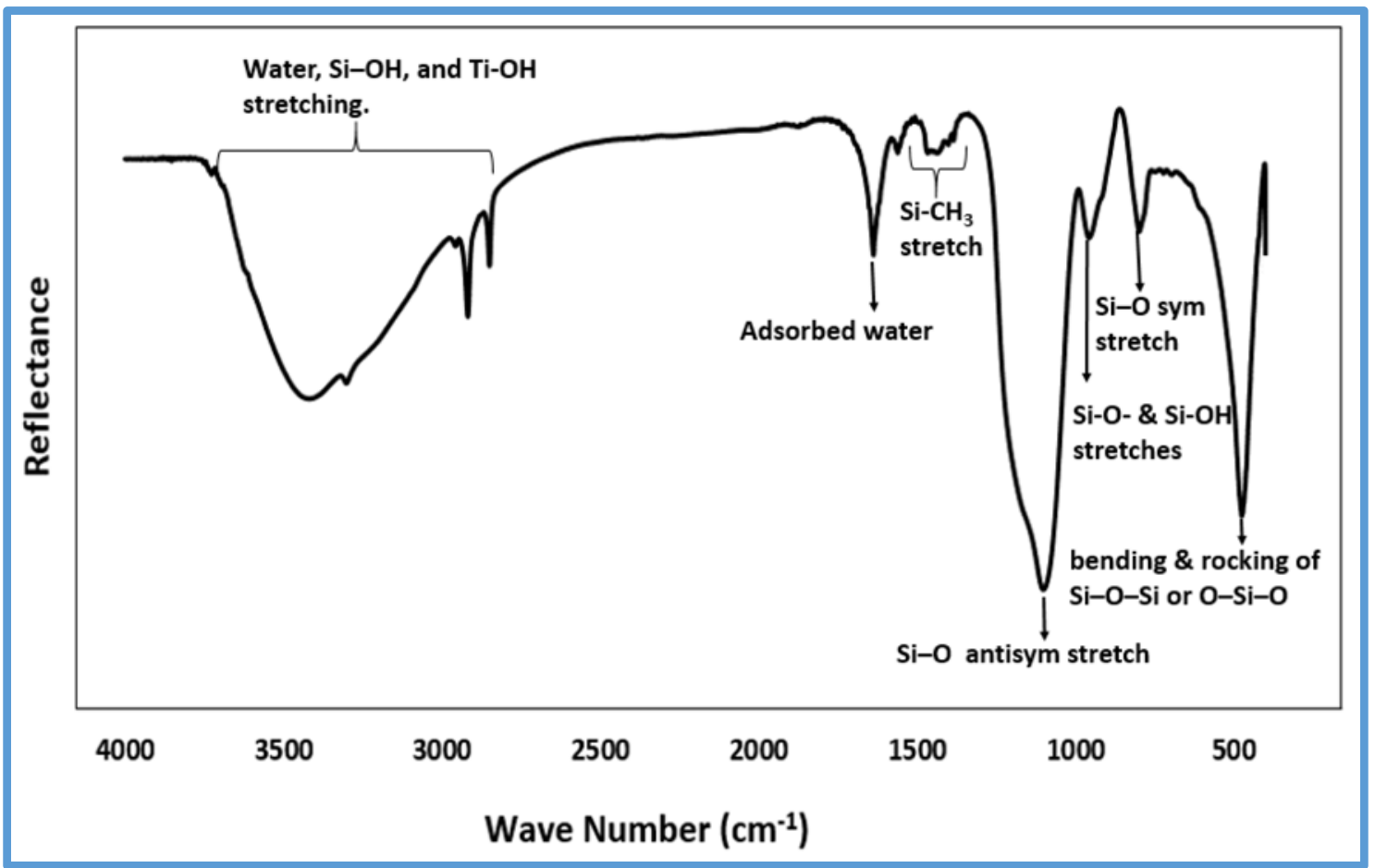

Fig. 3 FT-IR spectra of the TNFS membrane, which indicates the good hydrophilicity of the TNFS membranes made of titanate nanofibers and silica gel

Fig. 4 a A water contact angle of the TNFS membrane $\left(0^{\circ}\right)$. b An underwater oil contact angle of the TNFS membrane (156 \pm

$\left.1.6^{\circ}\right)$. c Dynamic water contact angle: water droplet behavior when water drops on the TNFS membrane

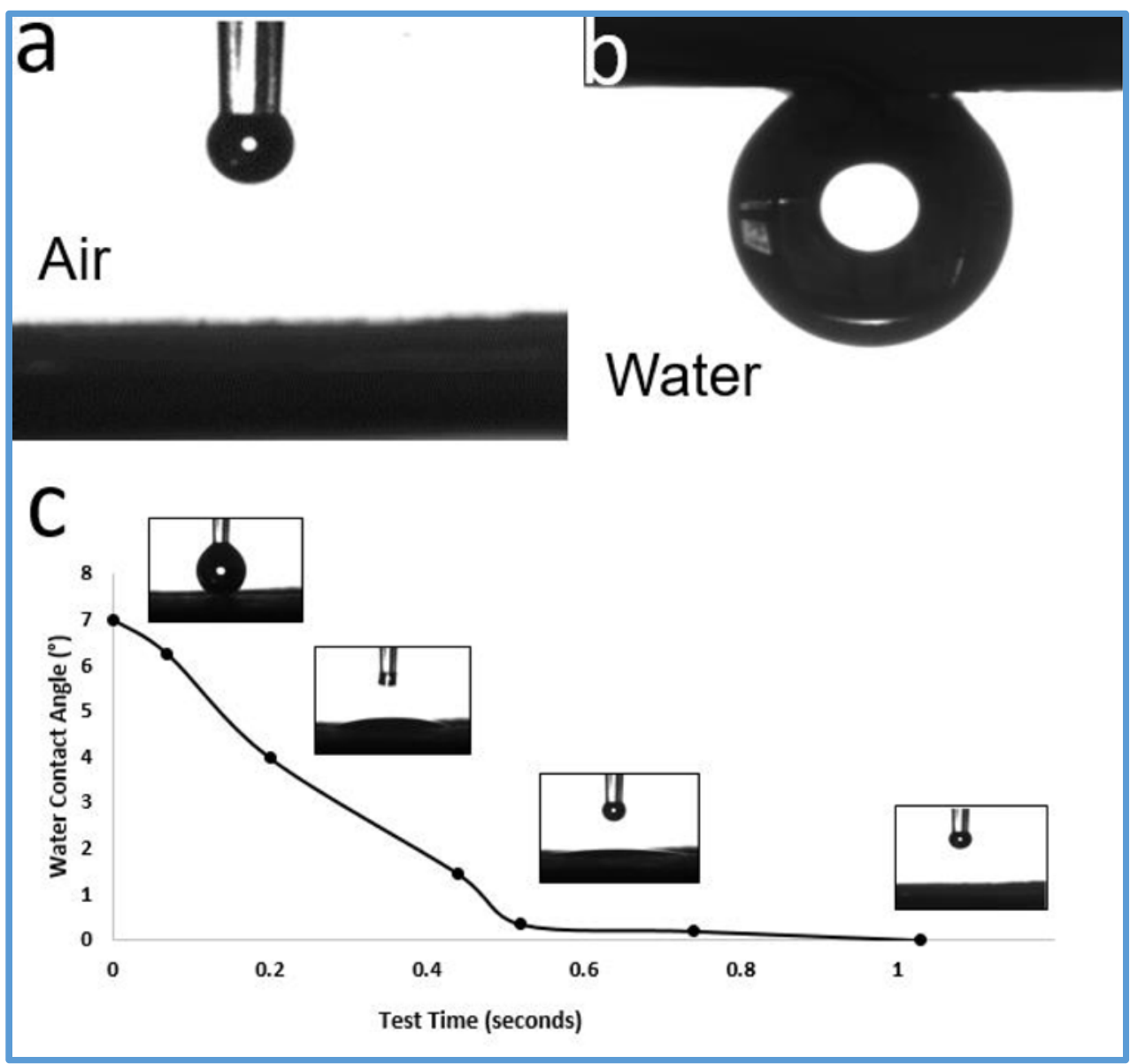


gasoline, octane, and hexane. Salinity in the emulsion feed was varied from $2500 \mathrm{ppm}$ to $45,000 \mathrm{ppm}$ by adding an appropriate amount of sodium chloride (Kayvani et al. 2018).

\section{Performance test}

The performance of the $\mathrm{TiNF} / \mathrm{SiO}_{2}$ membrane was evaluated based on the oil rejection and the permeate flux. The performance test studies were conducted by using a vacuum filtration apparatus where the operating pressure was fixed at vacuum pressure of $-30 \mathrm{kPa}$.

\section{Calculation procedure}

Flux calculation The flux through the membrane was demined using the following equation:

Flux $($ Lmh $/$ bar $)=\frac{V}{S t P}$

where $\mathrm{V}$ is the volume of the permeated water, $\mathrm{S}$ is the surface area of the membrane, $\mathrm{t}$ is the testing time, and $\mathrm{P}$ is the applied pressure.
Oil rejection The oil rejection will be calculated using the following equation:

$R(\%)=\left[1-\frac{C_{p}}{C_{f}}\right] \times 100$

where $\mathrm{R}$ is the rejection percentage, $\mathrm{C}_{\mathrm{f}}$ is the feed concentration, and $\mathrm{C}_{\mathrm{p}}$ is the permeate concentration. A TOC analyzer was used to measure oil content in the filtrate and feed water samples.

\section{Results and discussions}

\section{SEM}

Two types of all-inorganic nanostructured membranes were prepared, one with pure titanate nanofibers (TNF) and another with titanate nanofiber/silica gel (TNFS), respectively. The photographic images in Fig. 1 highlight the differences between TNF and TNFS membranes. Figure 1 al shows the cracked TNF membrane made out of pure titanate nanofibers without the addition of silica gel. This TNF inorganic membrane is fragile. Figure $1 \mathrm{a} 2$ and a 3 show the interconnected
Fig. 5 Photo images of oil-inwater emulsions before and after filtration by using the TNFS membranes. a1 A photo of the feed solution before filtration, and the oil was dyed in red. a2 A microscopic image of oil droplets in the feed solution before filtration. b1 A photo of the permeate solution after filtration by using the TNFS membranes. b2 A microscopic image of permeate solution after filtration, which shows that the solution becomes clear and that there are no visible oil droplets after filtration by using the TNFS membranes

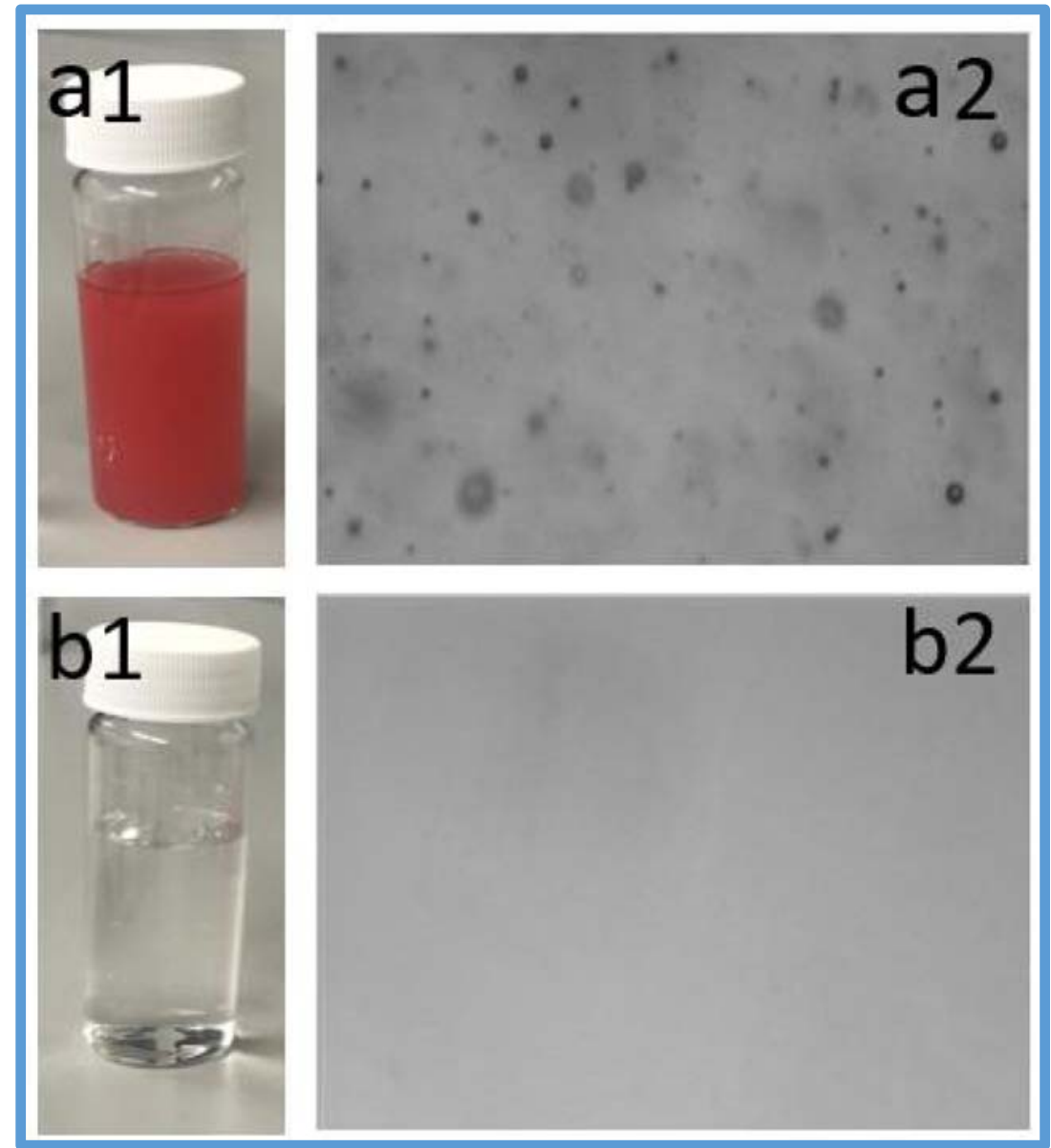


Fig. 6 a Performance tests for the TNFS membranes in terms of oil rejection and water flux with different oils and $\mathbf{b}$ oil concentrations in permeates, which are lower than US environmental discharge standards of $42 \mathrm{ppm}$

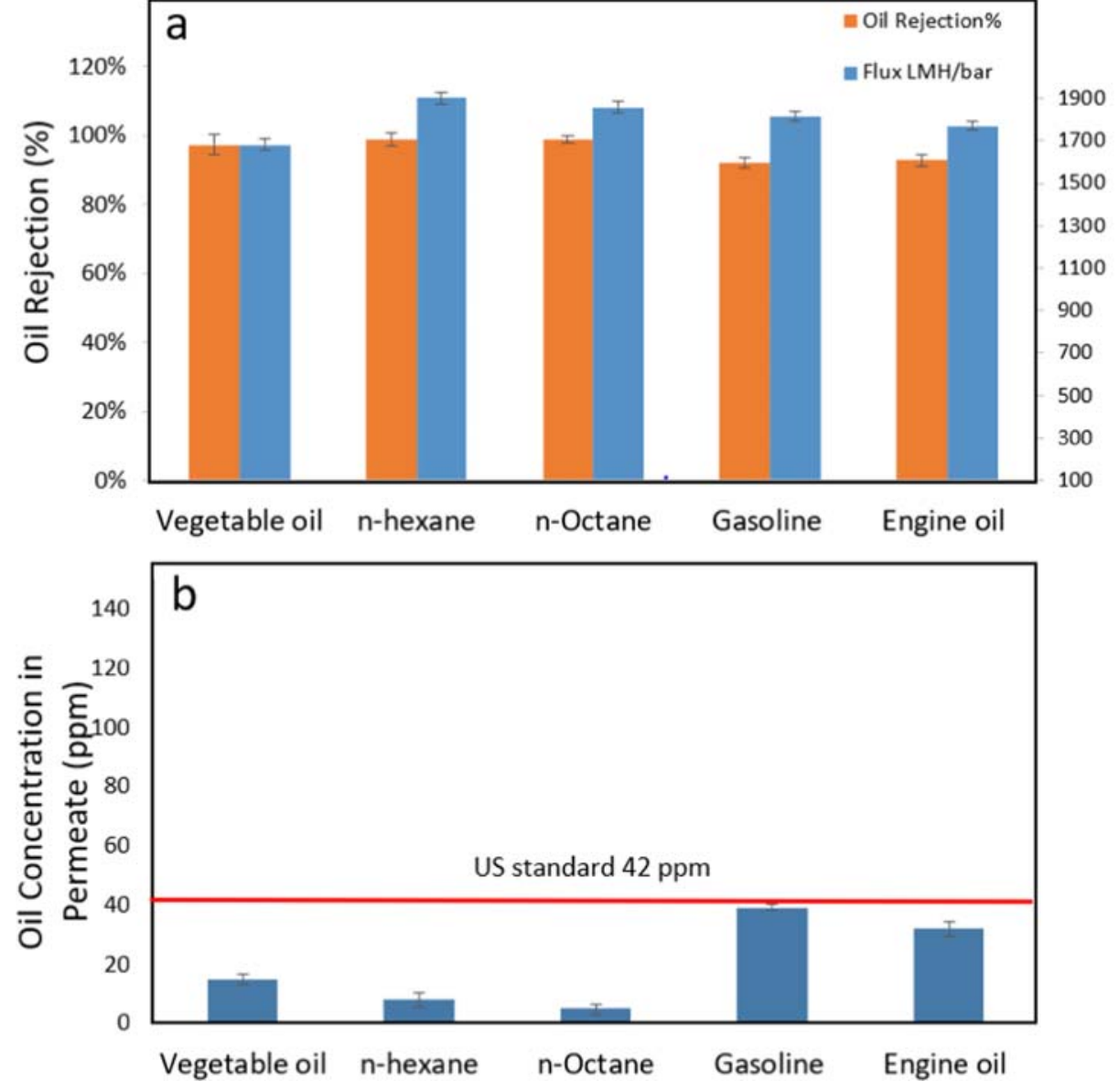

nanostructure of the TNF membrane constructed with titanate nanofibers. The 3D interconnected pore structure and tight pore size could render the membrane with high water flux and high oil rejection. The length and the diameter of the fabricated TNFs are $20 \mu \mathrm{m}$ and $100 \mathrm{~nm}$, respectively. Figure $1 \mathrm{~b} 1$ shows the photo of the flexible free-standing TNFS membrane made out of titanate nanofibers and silica gel. When silica nanoparticulate gel was coated to TNF membranes, as seen in the SEM of Fig. $1 \mathrm{~b} 3$, the flexibility of the membrane was significantly enhanced. The silica nanoparticulate gel functions as an inorganic binder on titanate nanofibers. The flexibility of the membranes is very important during practical industrial applications.

\section{XRD and EDS}

Figure 2 shows the XRD and the EDS analysis of the TNFS membrane. The obtained XRD profile of titanate and silica is in agreement with the findings of other literatures. The crystalline orientations of silica (111), (220), and (311) are clearly shown in Fig. $2 \mathrm{a}$, which correspond to $2 \theta^{\circ}$ of $25.5^{\circ}, 43.9^{\circ}$, and $55.6^{\circ}$, respectively (Aceves-Mijares et al. 2012; YasarInceoglu et al. 2012). The crystalline orientations which correspond to the anatase structure of the titanate are (101), (004),
(200), and (105) which correspond to $2 \theta^{\circ}$ of $25.5^{\circ}, 38.9^{\circ}$, $48.1^{\circ}$, and $52.7^{\circ}$, respectively (Yoon et al. 2017; Zhang et al. 2002). The crystalline orientations that correspond to the rutile structure of the titanate are (110) and (101) which correspond to $2 \theta^{\circ}$ of $29.5^{\circ}$, and $35.1^{\circ}$, respectively (He et al. 2015; Yoon et al. 2017). Figure $2 \mathrm{~b}$ shows an EDS analysis of the TNFS membrane, which further confirms the presence of the silica binder coated on the TNF-based membrane.

\section{FT-IR}

Figure 3 represents the FT-IR analysis of the TNFS membrane in the frequency range of $4000-550 \mathrm{~cm}^{-1}$. The purpose of the FT-IR analysis was to identify the functional groups on the material surfaces, which could provide the indication about hydrophilicity and hydrophobicity. This is because increasing the water concentration leads to a complete hydrolysis reaction of TEOS and the condensation reaction then forms a $2 \mathrm{D}$ linear chain and a $3 \mathrm{D}$ net structurer that contain a lot of $(-\mathrm{OH})$ groups. The peaks at $1100 \mathrm{~cm}^{-1}$ and $796 \mathrm{~cm}^{-1}$ correspond to Si-O antisymmetric and symmetric stretches, respectively (Brusatin et al. 1997). The peak at $957 \mathrm{~cm}^{-1}$ corresponds to $\mathrm{Si}-\mathrm{O}$ and $\mathrm{Si}-$ $\mathrm{OH}$ stretches (Rajput et al. 2012). The peak at $474 \mathrm{~cm}^{-1}$ 
Fig. 7 a Performance tests in terms of oil rejection and water flux under different salt concentrations and $\mathbf{b}$ oil concentrations in the permeates under different salt concentrations, which indicate that the TNFS membranes can effectively separate oil under different salty environments
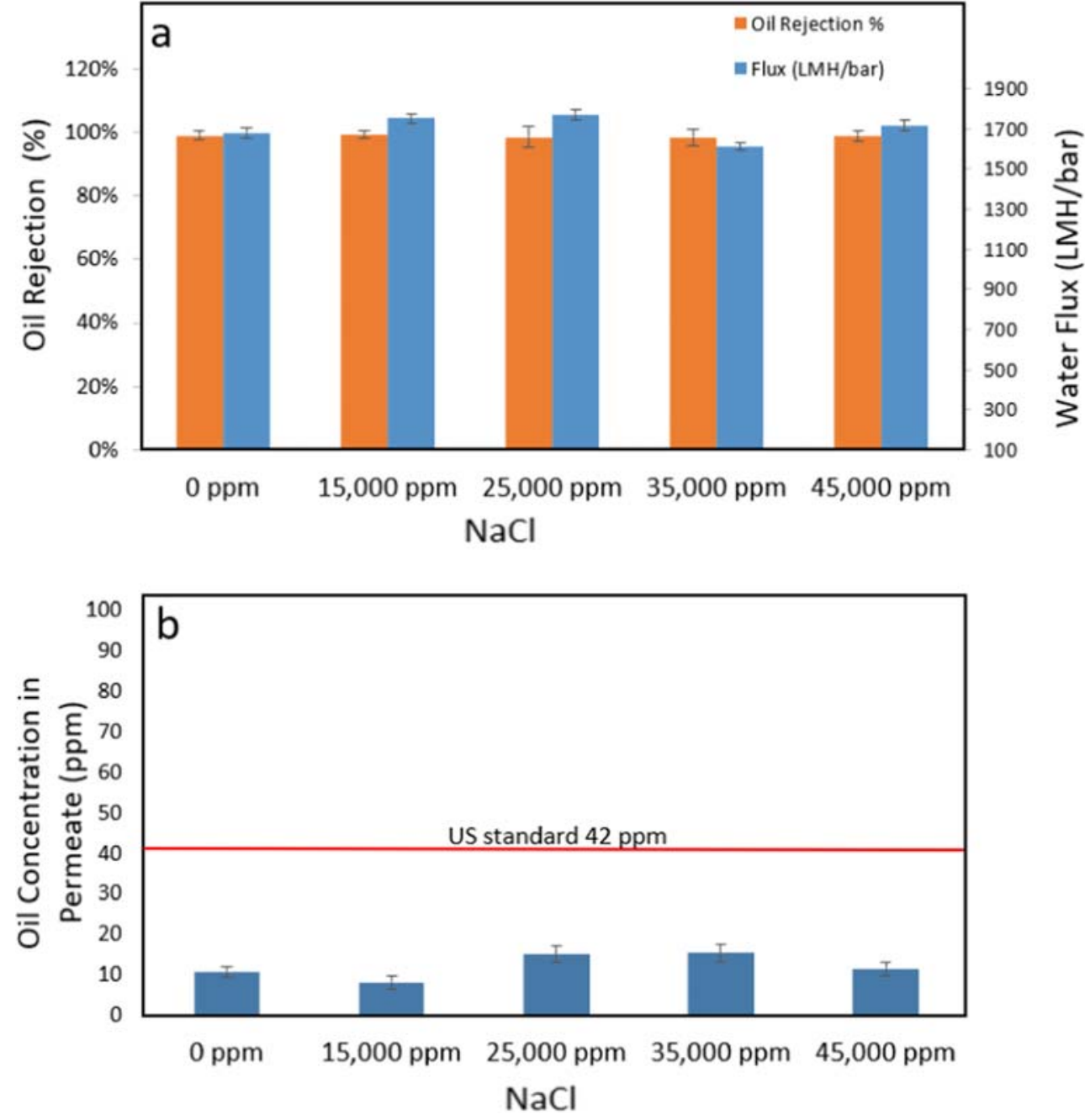

corresponds to the bending and rocking of Si-O-Si or OSi-O (Agarwal et al. 1995). The wide stretching band between $3700 \mathrm{~cm}^{-1}$ and $2840 \mathrm{~cm}^{-1}$ corresponds to water, Si$\mathrm{OH}$, and Ti-OH stretching (Sun et al. 2017). The peak at $1640 \mathrm{~cm}^{-1}$ corresponds to adsorbed water (Sárkány 2002), which indicates the good hydrophilicity of the membrane surfaces.

\section{Membrane wettability}

\section{Contact angle}

In order to assess the hydrophilicity of the membrane, it is important to perform a water contact angle (WCA) and an oil contact angle (OCA) (Sun et al. 2019; Yang et al. $2019 \mathrm{a}, \mathrm{b})$. The water droplet behavior was assisted by measuring the dynamic water contact angle when dropping the water on the TNFS membrane. As shown in Fig. 4, the contact angle measurements showed that the TNFS membrane has a water contact angle (WCA) of $0^{\circ}$, indicating the superhydrophilic property of this membrane. On the other hand, the underwater oil contact angle (OCA) was $156 \pm 1.6^{\circ}$, which indicates the underwater superoleophobicity of the membrane. The superhydrophilic and underwater oil-repelling surface of the new all-inorganic membrane is crucial in minimizing fouling caused by oil and organic substances.

\section{Performance test}

\section{Digital images before and after membrane treatment}

Figure 5 shows the photo images of the emulsified oil droplets in the feed and permeate solutions. The emulsified oil was dyed in red for visualization purposes. Before filtration, the VIPA microscopic image shows the existence of oil droplets in the emulsion, as seen in Fig. 5 a2. After filtration, the VIPA microscopic image shows the absence of oil droplets in the permeate after filtration by using the TNFS membranes, as seen in Figure $5 \mathrm{~b} 2$. This is a direct indication that the 
Fig. 8 The reusability test of the TNFS membrane. a Oil rejection and water flux as a function of 10 cycles of reuses. b Oil concentration in the permeate as a function of 10 cycles of reuses
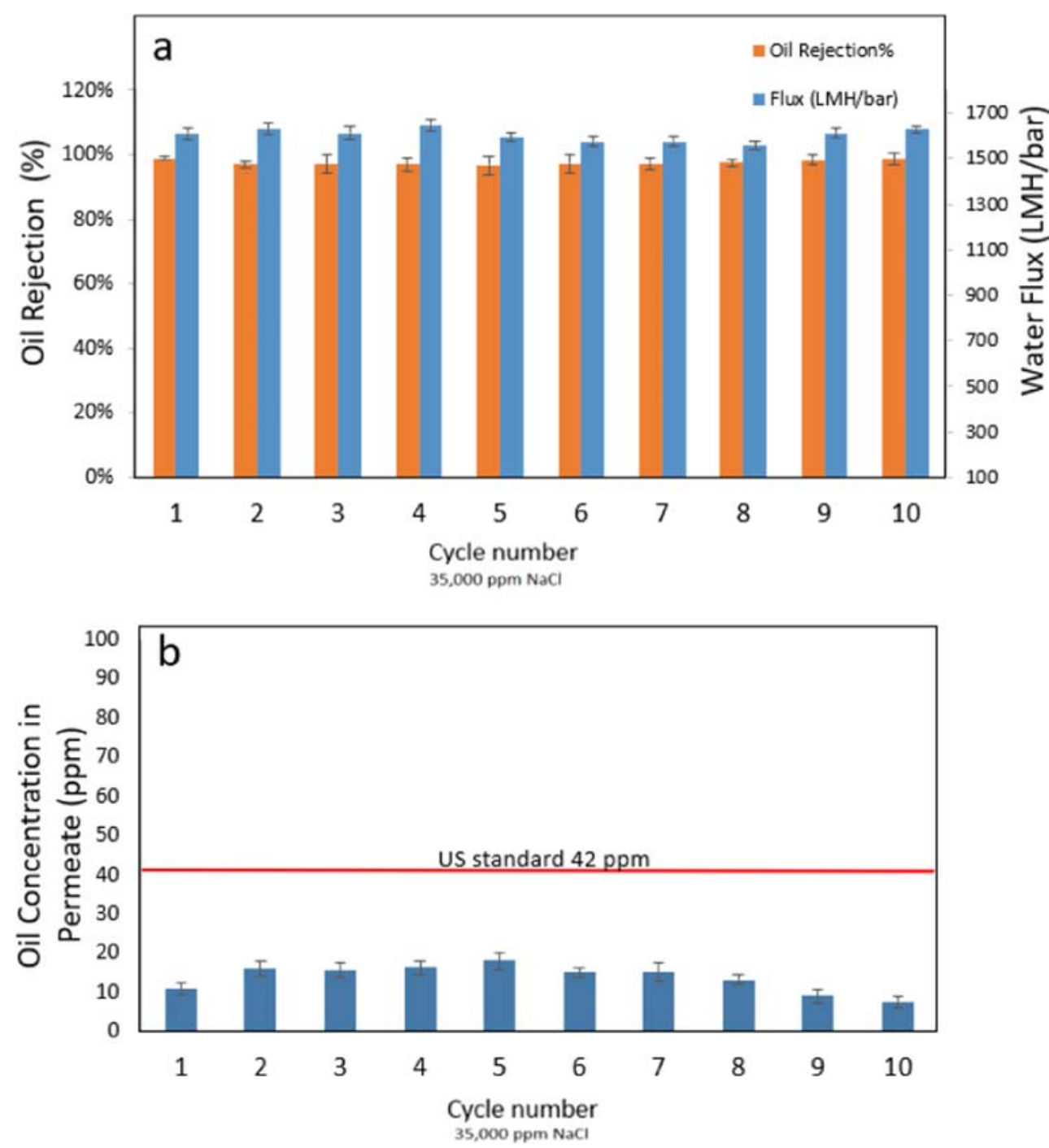

emulsified oil has been completely removed by using the TNFS membranes.

\section{Different oil}

Figure 6 shows the performance test results of the new TNFS membranes in terms of oil rejection and water flux. The different types of emulsified oil which include (i) vegetable oil (ii) n-hexane (iii) n-octene, (iv) gasoline, and (v) engine oil have been tested. The oil rejection is over $99 \%$ for all types of oils. It is worth to note that the oil concentrations in the permeates of the TNFS membranes are below the stringent oil discharge limit of $42 \mathrm{mg} / \mathrm{L}$ imposed by US EPA regulation. As shown in Fig. $6 \mathrm{~b}$, which indicates that it is safe to discharge the permeates to the environment, the high oil rejection rate could be due to the tight nanoporous structure of the new TNFS membranes.
According to Fig. 6a, the water fluxes ranged from 1681.4 LMH/bar to $1902.6 \mathrm{LMH} /$ bar. The water flux of these TNFS membranes is significantly higher than the reported water flux for polymer and ceramic membranes (Fan et al. 2015; Hu et al. 2004; Kayvani et al. 2018). The high water flux could be due to its 3D interconnected pore structure, which is easy for water to pass through.

\section{Salty environment tests}

It is important to test the membrane performance under different saline environments as oil-/gas-produced water and offshore oil spills which usually contain different levels of salinities. Figure 7 shows the performance test results of oil rejection and water flux under different salt concentrations. Figure $7 \mathrm{a}$ shows that the separation rates for the emulsified oil/water solutions can reach as high as $99 \%$ under different salinities. As shown in Fig. 7b, the oil concentrations in the permeates ranged between $8 \mathrm{ppm}$ and $15 \mathrm{ppm}$, which is lower 
than US EPA regulation limits (42 ppm). As shown in Fig. 7a, the high salinities did not affect the performances of the new TNFS membranes in terms of oil rejection rate and water flux.

\section{Reusability test}

The reusability of the TNFS membranes was tested over a period of 10 filtration cycles. As shown in Fig. 8, oil rejection rates remain constant at around over 99\% during all the 10 operating cycles. The oil contents in the permeate were consistently lower than the US EPA oil disposal limit (42 ppm).These results demonstrate the excellent durability of the TNFS nanocomposite membranes, as they are made out of all-inorganic materials. The superhydrophilic and oil-repelling surface of the TNFS membranes can be maintained consistently.

\section{Conclusions}

In this study, a new type of all-inorganic nanostructured TNFS membrane was presented for efficient and stable oil/saltwater separation. The new membrane displays high oil/water separation efficiency of above $99.5 \%$ with oil content in treated effluent lower than US environmental discharge standards (42 ppm) and high water permeation flux of $1600 \mathrm{LMH} / \mathrm{bar}$ under low operation pressure. Most importantly, the underwater superoleophobic property can be well maintained after repeated reuses in the environment of different salinities. The excellent separation efficiency, durability, fouling resistance, and low-cost fabrication render this new membrane with great potential for treating produced water and offshore oil spills.

Acknowledgments Open Access funding provided by the Qatar National Library. The authors would like to acknowledge the contribution of the Core Laboratory of Qatar Environment and the Energy Research Institute (QEERI) for the SEM, XRD, and FTIR characterizations of the materials.

Open Access This article is licensed under a Creative Commons Attribution 4.0 International License, which permits use, sharing, adaptation, distribution and reproduction in any medium or format, as long as you give appropriate credit to the original author(s) and the source, provide a link to the Creative Commons licence, and indicate if changes were made. The images or other third party material in this article are included in the article's Creative Commons licence, unless indicated otherwise in a credit line to the material. If material is not included in the article's Creative Commons licence and your intended use is not permitted by statutory regulation or exceeds the permitted use, you will need to obtain permission directly from the copyright holder. To view a copy of this licence, visit http://creativecommons.org/licenses/by/4.0/.

\section{References}

Aceves-Mijares, M., A. A. González-Fernández, R. López-Estopier, A. Luna-López, D. Berman-Mendoza, A. Morales, C. Falcony, C.
Domnguez, and R. Murphy-Arteaga. 2012. "On the origin of light emission in silicon rich oxide obtained by low-pressure chemical vapor deposition." J Nanomater 2012

Agarwal A, Davis KM, Tomozawa M (1995) A simple IR spectroscopic method for determining fictive temperature of silica glasses. J NonCryst Solids 185(1-2):191-198

Anon. 2010. 40 CFR 435.1 Environmental Protection Agency

Brusatin, G., M. Guglielmi, A. Martucci, G. Battaglin, S. Pelli, and G. Righini. 1997. "Microstructural and optical properties of sol-gel silica-titania waveguides." 220:202-9

Cai, Shuang, Yulu Zhang, Hongli Zhang, Hongwei Yan, Haibing Lv, and Bo Jiang. 2014. "Sol-gel preparation of hydrophobic silica antireflective coatings with low refractive index by base/acid two-step catalysis." 8-13

Fan JB, Song Y, Wang S, Meng J, Gao Y, Guo X, Lin F, Jiang L (2015) Directly coating hydrogel on filter paper for effective oil-water separation in highly acidic, alkaline, and salty environment. Adv Funct Mater 25(33):5368-5375

Feng L, Zhang Z, Mai Z, Ma Y, Liu B, Jiang L, Zhu D (2004) A superhydrophobic and super-oleophilic coating mesh film for the separation of oil and water. Angew Chem Int Ed 15(116):2046-2048

He G, Xie L, Yin GF, Zou YW, Liao XM, Huang ZB, Yao YD, Chen XC, Wang FH (2015) Comparison of Ca2+adsorption on (101) and (110) planes of rutile films: a combined theoretical and experimental investigation. Int J Electrochem Sci 10(9):7465-7477

$\mathrm{Hu}$ X, Bekassy-Molnar E, Koris A (2004) Study of modelling transmembrane pressure and gel resistance in ultrafiltration of oily emulsion. Desalination 163(1-3):355-360

Jung, Sung Mi, Hyun Young Jung, Wenjing Fang, Mildred S. Dresselhaus, and Jing Kong. 2014. "A facile methodology for the production of in situ inorganic nanowire hydrogels/aerogels"

Kayvani F, Ahmad AB, Jacobs M, McKay G, Atieh MA (2018) Novel hybrid ceramic/carbon membrane for oil removal. J Membr Sci 559(February):42-53

Obaid M, Kang Y, Wang S, Yoon M-H, Kim C-M, Songa J-h, Kim IS (2018) Fabrication of highly permeable thin-film nanocomposite forward osmosis membranes via the design of novel freestanding robust nanofiber substrates. J Mater Chem A 6(25):11700

Qin D, Liu Z, Baic H, Sun DD (2017) Three-dimensional architecture constructed from a graphene oxide nanosheet-polymer composite for high-flux forward osmosis membranes. J Mater Chem A 5(24): 12183-12192

Qin D, Liu Z, Sun DD, Song X, Bai H (2015) A new nanocomposite forward osmosis membrane custom-designed for treating shale gas wastewater. Sci Rep 5(September):1-14

Rajput D, Costa L, Terekhov A, Lansford K, Hofmeister W (2012) Silica coating of polymer nanowires produced via nanoimprint lithography from femtosecond laser machined templates. Nanotechnology 23(10)

Sakai T (2008) Surfactant-free emulsions. Curr Opin Colloid Interface Sci 13(4):228-235

Sárkány J (2002) Effects of water and ion-exchanged counterion on the FT-IR spectra of ZSM-5. Appl Catal A Gen 229(1-2):291-312

Shi Z, Zhang W, Zhang F, Liu X, Dong W, Jin J, Jiang L (2013) Ultrafast separation of emulsified oil/water mixtures by ultrathin freestanding single-walled carbon nanotube network films. Adv Mater 25(17):2422-2427

Sun H, Zhang Y, Sadam H, Ma J, Bai Y, Shen X, Kim J-k, Lu S (2019) Novel mussel-inspired zwitterionic hydrophilic polymer to boost membrane water-treatment performance. J Membr Sci 582(April): $1-8$

Sun J-Y, Zhao X, Illeperuma WRK, Chaudhuri O, Oh KH, Mooney DJ, Vlassak JJ, Suo Z (2012) Highly stretchable and tough hydrogels. Nature 489:133 
Sun S, Deng T, Ding H, Chen Y, Chen W (2017) Preparation of NanoTiO2-coated $\mathrm{SiO} 2$ microsphere composite material and evaluation of its self-cleaning property. Nanomaterials 7(11):367

Wang K, Han DS, Yiming W, Ahzi S, Abdel-Wahab A, Liu Z (2017a) A windable and stretchable three-dimensional all-inorganic membrane for efficient oil/water separation. Sci Rep 7(1):16081

Wang K, Yiming W, Saththasivama J, Liu Z (2017b) A flexible, robust and antifouling asymmetric membrane based on ultra-long ceramic/ polymeric fibers for high-efficiency separation of oil/water emulsions. Nanoscale 9(26):9018-9025

Xue Z, Wang S, Lin L, Chen L, Liu M, Lin F, Jiang L (2011) A novel Superhydrophilic and underwater Superoleophobic hydrogel-coated mesh for oil/water separation. Adv Mater 23(37):4270-4273

Yang X, Linlin Y, Jun M, Yongping B, Lu S (2019a) Bioadhesioninspired surface engineering constructing robust, hydrophilic membranes for highly-efficient wastewater remediation. J Membr Sci 591(July):117353

Yang X, Yan L, Wu Y, Liu Y, Lu S (2019b) Biomimetic hydrophilization engineering on membrane surface for highly-efficient water purification. J Membr Sci 589(July):117223

Yasar-Inceoglu O, Lopez T, Farshihagro E, Mangolini L (2012) Silicon nanocrystal production through non-thermal plasma synthesis: a comparative study between silicon tetrachloride and silane precursors. Nanotechnology 23(25):255604

Yoon SH, ElShorafa R, Katbeh M, Han DS, Jeong HW, Park H, AbdelWahab A (2017) Effect of shape-driven intrinsic surface defects on photocatalytic activities of titanium dioxide in environmental application. Appl Surf Sci 423:71-77

Zhang F, Zhang WB, Shi Z, Dong W, Jin J, Jiang L (2013) Nanowirehaired inorganic membranes with superhydrophilicity and underwater ultralow adhesive superoleophobicity for high-efficiency oil/ water separation. Adv Mater 25(30):4192-4198

Zhang Q, Liu N, Wei Y, Lin F (2018) Facile fabrication of hydrogel coated membrane for controllable and selective oil-in-water emulsion separation. Soft Matter 14(14):2649-2654

Zhang, Wenbin, Yuzhang Zhu, Xia Liu, Dong Wang, Jingye Li, Lei Jiang, and Jian Jin. 2014. "Salt-induced fabrication of superhydrophilic and underwater superoleophobic PAA-g-PVDF membranes for effective separation of oil-in-water emulsions." Angewandte Chemie (International Ed. in English) 53(3):856 - 860

Zhang, Y. X., G. H. Li, Y. X. Jin, Y. Zhang, J. Zhang, and L. D. Zhang. 2002. "Hydrothermal synthesis and photoluminescence of $\mathrm{TiO} 2$ nanowires." Chem Phys Lett 365(3-4):300-304

Zhu Y, Dong W, Jiang L, Jin J (2014) Recent progress in developing advanced membranes for emulsified oil/water separation. Npg Asia Materials 6:101

Publisher's note Springer Nature remains neutral with regard to jurisdictional claims in published maps and institutional affiliations. 